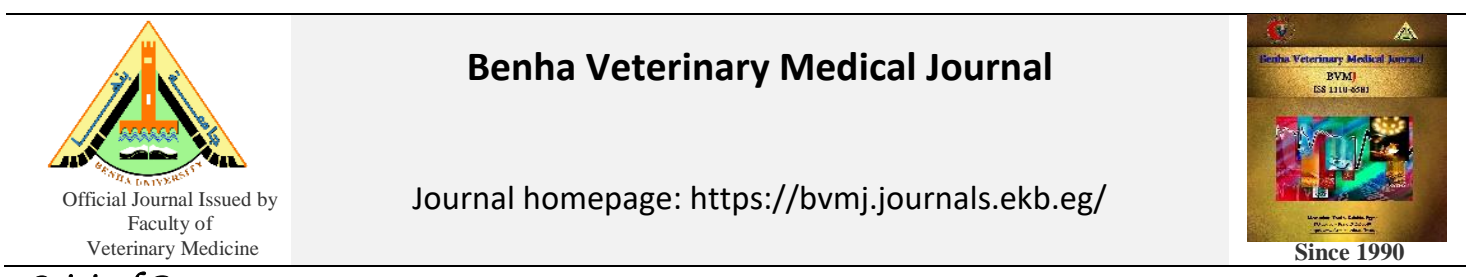

Original Paper

\title{
Extraction and characterization of Antigenic S- lipopolysaccharides Brucella abortus S99
}

Cleopatra M. Roushdy ${ }^{2}$, Mohamed G. Abdelwahab ${ }^{1}$, Abdel-Moneim M. Moustafa ${ }^{1}$, Faysal K. Ibrahim ${ }^{1}$, Essam M. El-bauomy ${ }^{2}$ and Mai A. Fadel ${ }^{2}$

${ }^{1}$ Faculty of Veterinary Medicine, Benha University, Egypt

${ }^{2}$ Animal Health Research Institute, Agriculture Research Center, Giza, P.O. 12618, Egypt.

\section{ARTICLE INFO}

\begin{tabular}{l}
\hline Keywords \\
Lipopolysaccharide \\
(LPS)/extraction \\
B. abortus $S 99$ \\
${ }^{\text {I}}$ H-NMR \\
Rabbit \\
Pyrogen test (RPT) \\
HPLC \\
\hline Received $06 / 06 / 2021$ \\
Accepted 30/06/2021 \\
Availa6le On-Line \\
01/10/2021
\end{tabular}

\begin{abstract}
Lipopolysaccharide (LPS)is the major valuable antigen used in diagnosis of brucellosis. In this study, to extract LPS from B. abortus strain 99 (reference strain), the hot-phenol method was used. Both chemical and biological characteristics were investigated to ensure quality and quantity of LPS to be involved in further diagnostic studies. Sugars represents about $50 \%$ of LPS $(0.57 \mathrm{mg} / \mathrm{mg})$. HPLC analysis of the extracted LPS revealed that its purity was the same as of the commercial LPS of Salmonella Typhimurium. To determine the chemical configuration of S-type LPS, Proton-nuclear magnetic resonance $\left({ }^{1} \mathrm{H}-\mathrm{NMR}\right)$ was used. The extracted LPS could be cleaved typically to yield a lipid A and polysaccharide moieties (two portions) as main structure of Gram-negative bacteria. A glucosamine sugar residue expanded on a wide range region of NMR spectrum. Considering biological features, Rabbit Pyrogen Test (RPT) of extracted LPS showed low pyrogenicity. While anti-complement activity of LPS was dose-dependent, high concentration caused high inhibition of hemolysis. Results emphasized the significance of these methods of extraction and characterization in obtaining valuable antigenic fraction LPS to be used in diagnosis or vaccination purposes.
\end{abstract}

\section{INTRODUCTION}

Brucellosis is one of the most important zoonotic and infectious disease worldwide and has a major hazard to human health and causes economic loss in animal industry sector (Seleem et al., 2010). According to the World Health Organization (WHO, 2006), it is one of the seven neglected zoonotic disease involved in a high portion in developing countries (PerezSancho et al., 2015). Brucella is a group of highly infectious gram-negative bacteria characterized by their ability to escape early recognition by innate immunity (Martirosyan et al., 2011). Hence, Brucella has capability to establish a chronic infection by escaping from both innate and adaptive immune response (Adem and Duguma, 2020).

Bacterial lipopolysaccharide (LPS) is a wellrecognized virulence factor of Gram-negative bacteria. So that LPS is of huge interest in medicine (Tan and Kagan, 2014). The relationship between chemical structure and virulence of LPS is an important aspect in research.

LPS typically consists of three different regions within different chemical and biological properties can be determined as follow: the lipid A (or endotoxin), a nonrepeating "core" oligosaccharide, and a distal O-specific polysaccharide O-PS or Oantigen (Raetz and Whitfield, 2002)

In many Gram-negative infectious diseases, although the endotoxicity of lipid A is of great significance, the saccharide domains of naturally occurring LPSs noticeably are also significant in affecting the pathophysiology (Rittig et al., 2003). Endotoxin (LPS), a global thermo-resistant toxin present in the outer membrane of the cell wall of Gram-negative bacteria, which causes various life-threatening diseases at low doses ( $\mathrm{Li}$ and Boraschi, 2016 and Elkhateeb et al., 2019)

As concern of serological diagnosis currently available, the major valuable antigen involved during vaccination and infection is the smooth LPS (Reyes et al., 2015).

The outermost portion of LPS; O-chain (OPS) is an immunodominant antigen (Poester et al., 2010). In many serological tests for brucellosis, various degrees of purity of LPS preparations have been used. Although specificity may be compromised in examination of sera from vaccinated animals, no alternative antigens could match the sensitivity achieved with LPS (Zygmunt et al., 1994). Most false positive serological reactions (FPSR) are a result of cross reaction with the OPS portion of the S-LPS molecule (OIE,2016)

Owing to the diagnostic significance of lipopolysaccharides in terms of their uses as an antigen in developing serological tests for Brucella, the present study was undertaken to extract lipopolysaccharide from reference strain $B$. abortus S99 and to study its characteristic chemical features using NMR and detection of purity by HPLC. Also,

\footnotetext{
*Corresponding author: roushdy_67@yahoo.com
} 
characterize the biological activity of LPS using Rabbit pyrogen test (RPT) and to assess anticomplement activity to understand the behavior of this antigen.

\section{MATERIAL AND METHODS}

2.1. Extraction of lipopolysaccharides (According to OIE, 2012)

The original strain of $B$. abortus strain 99 (NCTC 11363) was supplied by Central Veterinary Laboratory (now called Animal and Plant Health Agency, APHA), Weybridge, UK. Harvesting of $B$. abortus S99 on Tryptone soy agar (Oxoid, UK) was done according to Alton (1988).

\subsection{Chemical quantification of carbohydrate in LPS}

According to the quantitative colorimetric method of Du Bois et al. (1956)

2.3. Detection of purity of LPS using High performance liquid chromatography (HPLC)

It consists of Agilent Series 1200 quaternary gradient pump, Series 1200 autosampler, Series 1200 UV detector, and HPLC 2D Chem-station software (Hewlett-Packard, France). Extracted LPS concentration was assigned on calibrated standard curve. The working standards concentrations range were $0.5-10 \mu \mathrm{g} / \mathrm{ml}$. Extra-pure LPS standard extracted from Salmonella typhimurium was purchased from (Sigma, Saint Louis, USA). The chromatographic conditions were done according to Fadel and Hassan (2019).

2.4. Structural analysis of LPS using ${ }^{1} H-N M R$ (proton-magnetic resonance)

JNM-ECA500 II Spectrometer (JOEL Resonance Inc, Tokyo, Japan) operating at $500 \mathrm{MHz}$ with DELTA 2 data processing software and at a spinning rate of $11.3 \mathrm{kH}$. Sample $(5 \mathrm{mg})$ was lyophilized once from a deuterium oxide $\left(\mathrm{D}_{2} \mathrm{O}\right)$ solution and under conditions previously described by Bundle et al. (1987a). Chemical shifts were reported in parts/million. They were quoted and downfield coupling constants were reported in Hertz.

\subsection{Rabbit pyrogen assay}

It was carried out according to Rezania et al., (2011).

2.6. Anti-complement activity of LPS

It was determined according to Yokochi et al. (1990).

\section{RESULTS}

3.1. Chemical quantification of carbohydrate portion of LPS

The quantification revealed that extracted LPS from B. abortus $\mathrm{S} 99$ contain $0.57 \mathrm{mg} / \mathrm{mg}$ in comparison to reference sugar (D-glucose)
3.2. Checking purity of extracted B. abortus LPS using HPLC

The retention time of extracted LPS from $B$. abortus chromatogram was specified on 3.489 min. There was no compound interference between extracted LPS (Fig. 1) and pure standard Salmonella typhimurium LPS- Sigma, USA (Fig. 2). Using HPLC to ensure purity of LPS in comparison with standard LPS of Salmonella typhimurium, LPS was judged to be pure by giving similar peak to standard.

Figure (1): Chromatogram of extracted LPS of B. abortus $\mathrm{S} 99$.

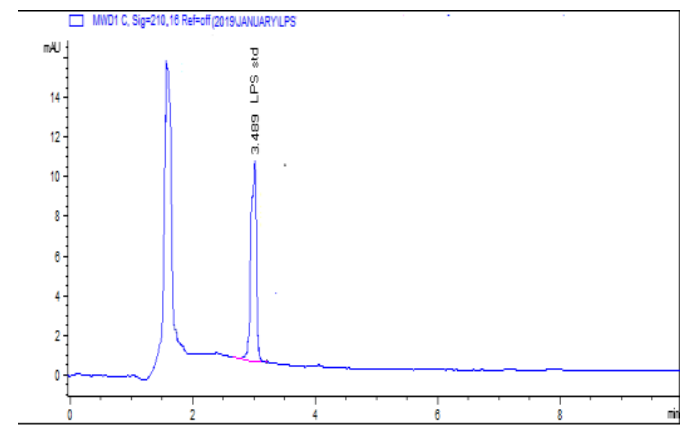

Figure (2): Chromatogram of pure LPS standard of S. typhimurium.

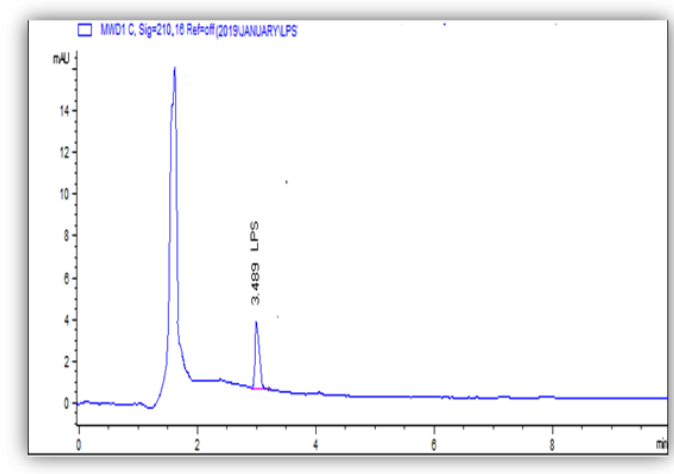

3.3. Chemical structure of LPS using ${ }^{1} \mathrm{H}$ NMRat $500 \mathrm{MHz}$

The lyophilized LPS was re-suspended in Deuterium oxide $\left(\mathrm{D}_{2} \mathrm{O}\right)$. LPS was pelleted by NMR rotor and applied for $500-\mathrm{MHz}{ }^{1} \mathrm{H}-\mathrm{NMR}$ spectrometer. The featured NMR signals were represented as different chemical groups of LPS (Fig. 3 a \& b). LPS consisted of 2 main portions, Lipid A, and polysaccharide. NMR spectrum showed signals of Lipid A portion extended from 0.8 to $2.6 \mathrm{ppm}$. It started with methyl $\left(\mathrm{CH}_{3}\right)$ and methylene $\left(\mathrm{CH}_{2}\right)$ signals at 0.8 and $1.2 \mathrm{ppm}$, respectively. Other chemical signals represented lipid A fatty acids. It was showed as $\mathrm{CH}=\mathrm{CH}-\mathrm{CH} 2, \mathrm{CH} 2-\mathrm{CO}$ (hydroxyl fatty acids) and $\mathrm{CH}-\mathrm{CH} 2-\mathrm{CH}$ (Cyclopropane) at 1.8, 2.2 and $2.6 \mathrm{ppm}$, respectively. The polysaccharide section was extended from 3 to $5.3 \mathrm{ppm}$. The anomeric proton signal (5.13 $\mathrm{ppm}$ ), characteristic of a-D-mannopyranosyl residues indicates that the native 0 -chain is a linear polymer of only 1,2-linked 4,6-dideoxy4-formamido-a-D-mannopyranosyl units. 


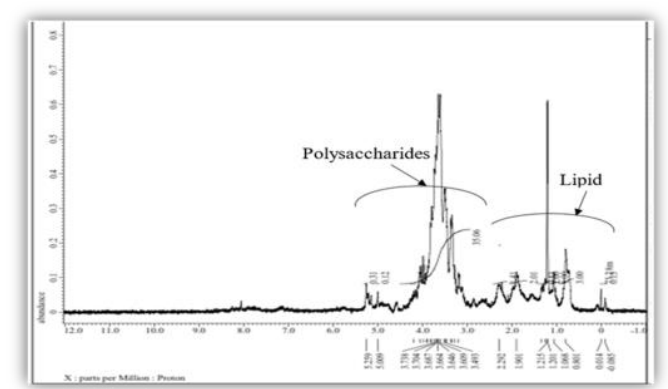

Figure (3 a): ${ }^{1} \mathrm{H}-\mathrm{NMR}$ spectrum recorded on a 500 $\mathrm{MHz}$ spectrometer used in characterization of $B$. abortus S 99 LPS.

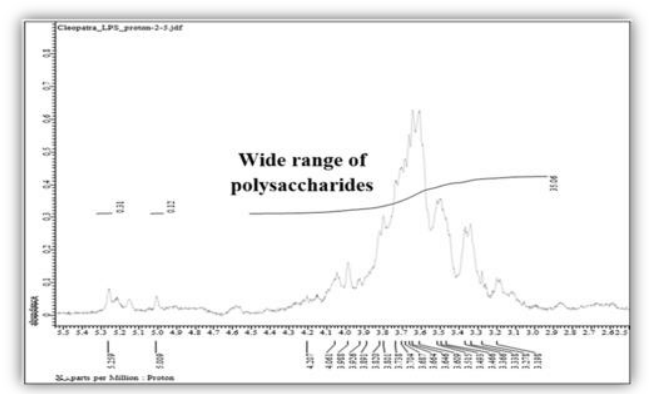

Figure $(3 \mathrm{~b})$ : Polysaccharide's spectrum using ${ }^{1} \mathrm{H}-$ NMR recorded at $500 \mathrm{MHz}$

\subsection{Results of pyrogenicity of LPS using Rabbit pyrogen test (RPT)}

The extracted LPS of B. abortus S99 elevated temperature of the examined three rabbits by the tune of $\left(1.23,1.58\right.$ and $\left.0.93^{\circ} \mathrm{C}\right)$ after three hours of injection. The recorded temperature was higher than the limit $\left(0.6^{\circ} \mathrm{C}\right)$ and the sum of maximum temperature of the examined three rabbits exceeds $1.4^{\circ} \mathrm{C}$. Results were interpreted according to International Pharmacopeia, (2019)

\subsection{Anti-complement activity of LPS}

LPS showed dose dependent anti-complement activity (Fig. 4). Higher concentration of LPS $(570 \mathrm{ug} / \mathrm{ml})$ produced high inhibition hemolysis that decreased remarkably at lower concentrations $(57,5.7,0.57 \mathrm{ug} / \mathrm{ml})$.

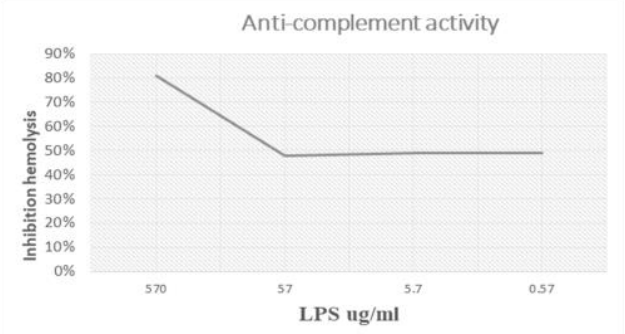

Fig (4): Anti-complement activity of different concentrations of LPS.

\section{DISCUSSION}

Unfortunately, LPS of $B$. abortus have not yet been commercially available, and those researchers who tend to conduct studies on LPS molecule to extract it using a proper method and characterized it by various methods of characterization. The hot-phenol method, and by using trichloroacetic acid to precipitate protein which is closely bind to LPS declared good efficiency of this method in extraction (Kalambhe et al., 2017)

Current study used Phenol-sulfuric acid method of $\mathrm{Du}$ Bois et al. (1956) as the most reliable colorimetric method extensively used in a wide range of fields to quantify carbohydrate content of LPS. Sugars content was $0.57 \mathrm{mg} / \mathrm{mg}$ LPS. LPS contained approximately 50\% w/w sugars. The obtained result agreed with those of Zankhari and Desai (2015) who studied LPS of Salmonella enterica serovar Typhi by hot phenol method and found that sugars constitute half of the weight of LPS.

Herein, whole LPS concentration was determined by simple, precise, economic, and rapid RP-HPLC with UV detector. It detected LPS in specific single peak within short retention time (3.4 min). Contrariwise, Qureshi et al., (1988) detected LPS in longer retention time (23 min.). LPS was calibrated on reference standard calibration curve based on validated method with low quantification limit (QL). This indicates high sensitivity. HPLC is a highly specified technique. Herein, the purity of extracted $B$. abortus LPS was detected as single peak in the same retention time of LPS standard of Salmonella typhimurium

Both LC-MS/MS and GC-MS are modern analytical technology were used for detection of LPS. They characterized by high selectivity, sensitivity, precision, and accuracy but very expensive with low availability in laboratories (Kivilompolo et al., 2007). LPS detected from $B$. abortus represent appropriate concentration which may be the main cause of inducing innate immunity of infected host (Casabuono et al., 2017).

The LPS structure of $B$. abortus was determined by NMR. The spectrum revealed full structure of LPS. LPS consist of 3 main components, including the $\mathrm{O}$-side chain, a middle polysaccharide component, and Lipid A. Lipid A is the most pyrogenic portion in bacteria (Schultz, 2018). NMR spectrum illustrated hydroxyl group and cyclopropane of fatty acids in Lipid A portion. Hydroxyl group has proven to be highly reactive (Ayala et al., 2014). Moreover, cyclopropane is very important for bacterial survival extracellularly, as well as facilitate the persistence in contaminated materials and transmission to new hosts (Palacios-Chaves et al., 2012).

A glucosamine sugar residue expanded on a wide range region of ${ }^{1} \mathrm{H}-\mathrm{NMR}$ spectrum. It is the main component of polysaccharide (Oantigen) with other sugar residues (KublerKielb, and Vinogradov, 2013). The 
polysaccharide potion has multiple NMR impulses made of free amino form of the 0 polysaccharide and its $\mathrm{N}$-acetylated derivative (Bundle et al., 1987b). The anomeric proton signal (5.13 ppm), which has a characteristic of a-D-mannopyranosyl residues (Choy and Dutton. 1973) seen in the ${ }^{1} \mathrm{H}-\mathrm{NMR}$ spectrum of extracted $B$. abortus LPS, indicates that the native 0 -chain is a linear polymer of only 1,2 linked 4,6-dideoxy-4-formamido-a-Dmannopyranosyl units.

The lipid A is synonymous with endotoxin which is responsible for most of the immunological activity of LPS even in picomolar concentrations, (Bryant et al., 2010). Rabbit pyrogen test (RPT) was the first method approved by the Food and Drug Administration (FDA) for Lipopolysaccharide testing. In the present study, the pyrogenicity of our extracted LPS of B. abortus S99 was evaluated. Following the interpretation of International Pharmacopeia (2019), LPS was pyrogenic in a dose of $25 \mu \mathrm{g} / \mathrm{ml}$ that indicated by elevation of the temperature of examined rabbits beyond the limit $0.6^{\circ} \mathrm{C}$ for individual rabbit or $1.4^{\circ} \mathrm{C}$ for the examined three rabbits. Less toxic and low pyrogenic nature of LPS of B. abortus S99 in comparison to other bacterial LPS can indicate its promising aspect of its application as a new adjuvant in vaccine study with microbial origin (Kianmehr et al., 2015). LPS of B. abortus may be a useful candidate as a component of vaccines because it has several characteristic properties as a carrier that enable it to stimulate human B cells (Goldstein et al., 1992). LPS (non- classical) extracted from Brucella strains is less toxic and less active than the classical LPS isolated from E. coli and Salmonella. These characters allow evasion of Brucella from innate immunity and being a weak inducer of tumor necrosis factor (Christopher et al., 2010). On contrary, Reyes et al. (2015) excluded the clinical use of LPS as an immunological carrier because of its toxicity and pyrogenicity.

The anti-complement activity of LPS of B. abortus was dose dependent. It increased in higher concentration and dramatically decreased after ten-fold dilution (570, 57, 5.7 and $0.57 \mathrm{ug} / \mathrm{ml}$ ). It is mainly attributed to the $\mathrm{O}$ specific polysaccharide or core polysaccharide (Tumurkhuu et al., 2006). The previous studies by Tomas et al. (1988) found a correlation between inhibitory effect of LPS on serum bactericidal activity and the anti-complement activity, measured as the percentage inhibition of hemolysis with sensitized erythrocytes (Goldmann et al., 1984).

The high anti-complement activity of $B$. abortus LPS may be useful for the survival of
Brucella since complement exhausted at sites removed from the outer membrane surface (Ficht, 2003). Brucella LPS was reported to fail in the activation of the alternative pathway of complement (Fernandez-Prada et al., 2001)

\section{CONCLUSION}

The results of current study emphasized some chemical and biological characters of extracted B. abortus S99 LPS to be incorporated in serological diagnosis of brucellosis.

\section{Conflict of interest}

The authors declare that there are no conflicts of interest.

\section{Acknowledgment}

We are most grateful to all members of NMRunit, Faculty of Science, Mansoura University, for their kind contribution of NMR analysis.

\section{REFERENCES}

1. Adem, A., Duguma, A. 2020. Characteristics and Intracellular Life of Brucella Organism: A Review. $J$. Microb. Biochem. Technol., 12 (3):431. Doi: 10.35248/1948-5948.20.12.431

2. Alton, G.G., Jones, L.M., Angus, R.D., and Verger, J.M. 1988. Techniques for the Brucellosis Laboratory. Institut National de la Recherche Agronomique (INRA) 75007, Paris, France. ISBN: 2738000428

3. Ayala, A., Muñoz, M. F., and Argüelles, S. 2014. Lipid peroxidation: production, metabolism, and signaling mechanisms of malondialdehyde and 4-hydroxy-2nonenal. Oxid. Med. Cell. Longev., 360438. Doi: $10.1155 / 2014 / 360438$

4. Bryant, C.E., Spring, D.R., Gangloff, M. and Gay, N.J. 2010. The molecular basis of the host response to lipopolysaccharide. Nat Rev Microbiol., 8(1), 8-14.

5. Bundle, D. R., Cherwonogrodzky, J. W. and M. B. Perry. 1987 a Structural elucidation of the Brucella melitensis $\mathrm{M}$ antigen by high resolution nuclear magnetic resonance at $500 \mathrm{MHz}$. Biochemistry, 26, $8717-8726$

6. Bundle, D. R., Cherwonogrodzky, J. W. and Perry, M. B. 1987 b. The structure of the lipopolysaccharide Ochain ( $\mathrm{M}$ antigen) and polysaccharide $\mathrm{B}$ produced by Brucella melitensis 16M. FEBS letters, 216(2), 261264.

7. Casabuono C., Czibener C., Del Giudice M. G., Valguarnera E., Ugalde J. E. and Couto A. S. 2017. New Features in the Lipid A Structure of Brucella suis and Brucella abortus Lipopolysaccharide. J. Am. Soc. Mass Spectrom. 28, 2716-2723.

8. Choy, V. M., and Dutton, G. G. A. 1973. The structure of the capsular polysaccharide from Klebsiella K-type 21. Can. J. Chem., 51,198-207.

9. Christopher, S., Umapathy, B.L., Ravikumar, K.L. 2010. Brucellosis: Review on the recent trends in pathogenicity and laboratory diagnosis. J. Lab. Physicians, 2, 55-60.

10.Du Bois, M., Gilles, K., Hamilton, J., Rebers, P., and Smith, F. 1956. Colorimetric method for determination of sugars and related substances. Analytical Chemistry, 28(3), 350-356.

11.Elkhateeb, M.A., Elkhatib, W.F., Aboulwafa, M.M. 2019. An expert review on current approaches for endotoxin detection in various biological products. Arch. Pharm. Sci. Ain Shams University, 3(2), 142153. 
12. Fadel, M. A. and Hassan, H. M. 2019. Validated method for extraction and purification of Lipopolysaccharide from Escherichia coli and Salmonella by HPLC. Anim. Health Res. J., 7 (4): 110.

13. Fernandez-Prada, C.M., Nikolich, M., Vemulapalli, R., Sriranganathan, N., Boyle, S.M., Schurig, G.G., Hadfield, T.L. and Hoover, D.L. 2001. Deletion of wboA enhances activation of the lectin pathway of complement in Brucella abortus and Brucella melitensis. Infect. Immun., 69, 4407-4416.

14. Ficht, T.A. 2003. Intracellular survival of Brucella: defining the link with persistence. Vet. Microbiol, 92 213-223.

15. Goldmann, R.C., Joinier, K. and Leive, L. 1984 Serum-resistant mutants of Escherichia coli 0111 contain increased lipopolysaccharide, lack of 0 antigen containing capsule and cover more of their lipid A core with 0-antigen. J. Bacteriol., 159(3), 877882 .

16. Goldstein J., Hoffman, T., Frasch, C., Lizzio, E.E F., Beining, P. R., Hochstein, L.D., Lee, Y.L., Angus, R.D., and Golding, B.1992. Lipopolysaccharide (LPS) from Brucella abortus is Less Toxic than That from Escherichia coli, Suggesting the Possible Use of $B$. abortus or LPS from $B$. abortus as a Carrier in Vaccines. Infect. Immun. 60 (4), 1385-1389.

17. International Pharmacopoeia 2019. Test for pyrogens. $9^{\text {th }}$ Edition. https://apps.who.int/phint/pdf/b/7.3.5.3.5 Test-for-pyrogen

18. Kalambhe, D.G., Zade, N.N., and Chaudhari, S.P. 2017. Evaluation of Two Different Lipopolysaccharide Extraction Methods for Purity and Functionality of LPS. Int. J. Curr. Microbiol. App. Sci., 6(3): 12961302.

19. Kianmehr, Z., Kaboudanian Ardestani, S., Soleimanjahi, H., Fotouhi, F., Alamian, S., and Ahmadian, S. 2015.Comparison of Biological and Immunological Characterization of Lipopolysaccharides from Brucella abortus RB51 and S19. Jundishapur J. Microbiol., 8(11), e24853.

20. Kivilompolo, M., Obůrka, V., and Hyötyläinen, T. 2007. Comparison of GC-MS and LC-MS methods for the analysis of antioxidant phenolic acids in herbs. Analytical and bioanalytical chemistry, 388(4), 881-887.

21. Kubler-Kielb, J., and Vinogradov, E. 2013. The study of the core part and non-repeating elements of the $\mathrm{O}$ antigen of Brucella lipopolysaccharide. Carbohydrate research, 366, 33-37.

22.Li, Y., and Boraschi, D. 2016. "Endotoxin Contamination: A Key Element in the Interpretation of Nanosafety Studies." Nanomedicine, 11: 269-287.

23. Martirosyan, A., Moreno, E. and Gorvel, J.P. 2011. An evolutionary strategy for a stealthy intracellular Brucella pathogen. Immunol Rev 240, 211-234.

24. OIE 2012. Manual of Diagnostic Tests and Vaccines for Terrestrial Animals, Chapter: 2.4.3. Bovine brucellosishttp://www.oie.int 2.4.3 bovine brucellosis

25. OIE 2016. Manual of Diagnostic Tests and Vaccines for Terrestrial Animals, Chapter: 3.1.4 Brucellosis (infection with B. abortus, B. melitensis and B. suis).

26. Palacios-Chaves, L., Zuniga-Ripa, A., Gutierrez, A. Gil-Ramirez, Y., Conde-Alvarez, R., Moriyon, I., and Iriarte, M. 2012. Identification and functional analysis of the cyclopropane fatty acid synthase of Brucella abortus. Microbiology, 158(4), 1037-1044.

27.Perez-Sancho, M., Garcia-Seco, T., Dominguez, L. and Alvarez, J. 2015. Control of animal brucellosis: the most effective tool to prevent human brucellosis, updates on Brucellosis. Manal Mohammad Baddour (Ed.), InTech (2015), 10.5772/61 222
28. Poester, F.P.; Nielsen, K.; Samartino, L. E. and Yu, W. L. 2010. Diagnosis of Brucellosis. The Open Veterinary Science Journal, 4: 46-60.

29. Qureshi, N., Takayama, K., Mascagni, P., Honovich, J., Wong, R. O. N. G., \& Cotter, R. J. 1988. Complete structural determination of lipopolysaccharide obtained from deep rough mutant of Escherichia coli. Purification by high performance liquid chromatography and direct analysis by plasma desorption mass spectrometry. Journal of Biological Chemistry, 263(24), 11971-11976.

30.Raetz, C.R., Whitfield, C. 2002. Lipopolysaccharide endotoxins. Annu. Rev. Biochem., 71, 635-700.

31. Reyes, A. W. B.; Simborio, H. L. T.; Hop, H. T.; Arayan, L. T.; Huy, T.X. N.; Min, W. and Kim, S. 2015. The two highly immunogenic antigens of Brucella: lipopolysaccharide (LPS) and outer membrane proteins (OMPs). J. Prev. Vet. Med., 39(4), 198-206.

32. Rezania, S., Amirmozaffari, N., Tabarraei, B., JeddiTehrani, M., Zarei, O., Alizadeh, R., Masjedian F. and A. Zarnani, H. 2011. Extraction, purification and Characterization of Lipopolysaccharide from Escherichia coli and Salmonella typhi. Avicenna J. Med. Biotech., 3(1), 3-9.

33. Rittig, M. G., Gemsa, D., Kaufmann, A., Foulongne, V., Robins, A., Rouot, B., Shaw, B., Sprenger, H.and Dornand, J. 2003. Smooth and rough lipopolysaccharide phenotypes of Brucella induce different intracellular trafficking and cytokine/chemokine release in human monocytes. Journal of Leukocyte Biology, 74, 1045-1055.

34.Schultz, C. 2018. Lipopolysaccharide, structure, and biological effects. Gen. Int. Med. Clin. Innov., 3(1): 12 .

35. Seleem, M. N., Boyle, S. M., and Sriranganathan, N. 2010. Brucellosis: a re-emerging zoonosis. Veterinary microbiology, 140(3-4), 392-398.

36. Tan, Y. and Kagan, J.C. 2014. A cross-disciplinary perspective on the innate immune responses to bacterial lipopolysaccharide. Molecular Cell., 54 (2), 212-223.

37. Tomas, J. M., Ciurana, B., Bened, V. J. and Juarez, A. 1988. Role of Lipopolysaccharide and Complement in Susceptibility of Escherichia coli and Salmonella typhimurium to Non-immune Serum. Journal of General Microbiology, 134, 1009-1016.

38. Tumurkhuu, G., Koide, N., Takahashi, K., Hassan, F., Islam, S., Ito, H., Mori, I., Yoshida, T., Yokochi, T. 2006. Characterization of biological activities of Brucella melitensis lipopolysaccharide. Microbiol Immunol., 50(6), 421-427.

39.WHO, 2006. The control of neglected zoonotic diseases. A route to poverty alleviation. Report of a Joint WHO/DFID-AHP. Meeting with the participation of FAO and OIE, Geneva. https://www.who.int/zoonoses/Report_Sept06.

40. Yokochi, T., Inoue, Y., Kimura, Y. and Kato, N. 1990. Strong interaction of lipopolysaccharides possessing the mannose homopolysaccharides with complement and its relation to adjuvant action. Journal of immunology, 144(8), 3106-3110.

41. Zankharia, U. S., Desai P.V. 2015.Chemical Analysis of lipopolysaccharide extracted from Salmonella enterica serovar Typhi. IJRSI. II (VI): 7578.

42. Zygmunt, M. S., Cloeckaert, A. and Dubray, G.1994. Brucella melitensis cell envelope protein and lipopolysaccharide epitopes involved in humoral immune responses of naturally and experimentally infected sheep. J. Clin. Microbiol. 32, 2514-252. 